\title{
A survey of teaching and the use of clinical guidelines in accident and emergency departments
}

\author{
P Hormbrey, B S Todd, C D Mansfield, D V Skinner
}

\begin{abstract}
Objective-To investigate organised teaching in accident and emergency (A\&E) departments in England and Wales.

Methods-A survey was carried out by postal questionnaire. Directed to senior house officers (SHOs), the questionnaire examined the nature and extent of departmental teaching, and measured the availability, suitability, and actual use made of guidelines. Of 231 questionnaires sent, 164 were returned (response rate $71 \%$ ).

Results-The results show that most SHOs attended $A \& E$ induction courses at the beginning of their attachments, although the scope of these courses varied widely. Most SHOs also received regular teaching, although the programmes were generally of less than $3 \mathrm{~h}$ in duration. The majority of respondents were well supported with written documentation in a variety of formats. However, a significant minority $(29 \%)$ of SHOs requested more detailed clinical guidance, and these tended to be the respondents who received the most departmental teaching.

Conclusions-More time could be allocated to structured teaching than at present, and greater use made of complementary educational methods such as practical skill teaching, case presentation, clinical audit, and involvement in journal clubs. More extensive departmental teaching should also be supported by making available more detailed and comprehensive clinical guidelines.

(f Accid Emerg Med 1996;13:129-133)
\end{abstract}

Accident and

Emergency

Department, John

Department, John
Radcliffe Hospital,

Oxford

P Hormbrey

D V Skinner

Oxford University

Computing Laboratory

B S Todd

Postgraduate Medical

School, Oxford

C D Mansfield

Correspondence to:

P Hormbrey,

Senior Registrar in

Accident and Emergency

Medicine, Accident and

Emergency Department,

John Radcliffe Hospital,

Headley Way, Headington,

Oxford OX $39 \mathrm{DU}$

United Kingdom.
Key terms: accident and emergency medicine; clinical guidelines; induction course; questionnaire survey; teaching

Nowhere would organised teaching seem to be more necessary than in accident and emergency $(A \& E)$ medicine, given the wide range of conditions seen, the relative inexperience of $A \& E$ junior staff, and the high turnover rate of senior house officers (SHOs). For example, in one study of a major A\&E department, the judged to be "poor". ${ }^{1}$ In another study, 39\% of clinically important radiological signs were missed by A\&E SHOs. ${ }^{2}$ However, in practice it is often difficult to reconcile the need for adequate teaching programmes with the management of as many as one in 10 cases was impediment of complicated timetabling constraints and high service demands. Therefore, how much teaching do SHOs actually receive? Is this sufficient, and could the time allocated to teaching be used more efficiently? Are SHOs adequately supported by reference material, or are more comprehensive clinical guidelines required too?

To address these questions we carried out a survey of A\&E departments in England and Wales. Traditionally, A\&E teaching has consisted of two components, an induction course at the start of each SHO's attachment, and regular departmental teaching during the attachment. We sought to quantify the nature and extent of both of these. We also measured the extent to which SHOs refer to reference sources for management advice, and the types of clinical guidelines actually available. Finally we surveyed attitudes of SHOs to clinical guidelines, and we related the perceived adequacy of the available guidelines to the amount of teaching received.

\section{Methods}

We surveyed $A \& E$ departments by means of a postal questionnaire, identifying departments listed by the British Association for Accident and Emergency Medicine (BAAEM). ${ }^{3}$ Our admission criteria to the study were: (1) the A\&E department was in England or Wales; (2) the A\&E department had SHOs; (3) the A\&E department was general (that is, not confined to the treatment solely of ophthalmic, ENT, orthopaedic, or paediatric conditions).

Where a department was not listed as having SHOs, but dealt with 10000 or more new attendances per year (or the figure was unavailable), we telephoned the department to enquire whether the staff included SHOs.

The questionnaire contained 23 questions, divided as follows.

(1) The nature of any induction course (questions 1 and 2).

(2) The extent of continuing departmental teaching (questions 3,4 , and 5).

(3) The availability, frequency of use, and adequacy of clinical guidelines (questions $6,7,8$, and 9).

(4) Questions relating to a specific guideline on asthma management that was enclosed (questions 10-23).

In this paper we examine the responses only to the first nine questions (listed in the appendix), the subsequent 14 questions form 
part of a separate study on guidelines that will be reported elsewhere. We set out to achieve as high a response rate as reasonably possible. We therefore sent the questionnaire to the clinician (usually a consultant) in charge of the department. The letter briefly outlined the nature of the study, and requested that the questionnaire be passed to an SHO to complete and return. The letter explained that all replies received within the first three weeks would be included in a draw for 10 copies of a recent book of case presentations in accident and emergency medicine. ${ }^{4}$ The letter also explained that the results of the survey would be circulated to all respondents who supplied their names and addresses. Strict confidentiality was promised. Our objective was to obtain a response from one SHO at each A\&E department during the six month period 1 August 1994 to 31 January 1995, representing one of the two usual attachments for SHOs each year. The majority of questionnaires were sent out at the end of August. Reminders were sent out as necessary six weeks later. At the beginning of December, we began to telephone all departments from which a reply had still not been received in case the questionnaires had been lost. Figure 1 summarises the survey process. The questionnaire responses were analysed using an SPSS statistical package.

\section{Results}

A total of 231 questionnaires was sent initially and 121 of these were returned, although two were spoilt. We attempted to contact the nonresponding sites by sending reminders and telephoning (although often we were unsuccessful because the lines were engaged or because no-one was available who could take our call). Following this, 45 further questionnaires were returned. The final response rate was thus $71 \%(164 / 231)$.

Analysis of the 164 questionnaires that were returned unspoilt showed that $90 \%(148 / 164)$ of the respondents had attended an induction course specific to $A \& E$ (question 1 ). Only $9 \%$ $(15 / 164)$ of the respondents had not attended an $A \& E$ induction course, and one respondent

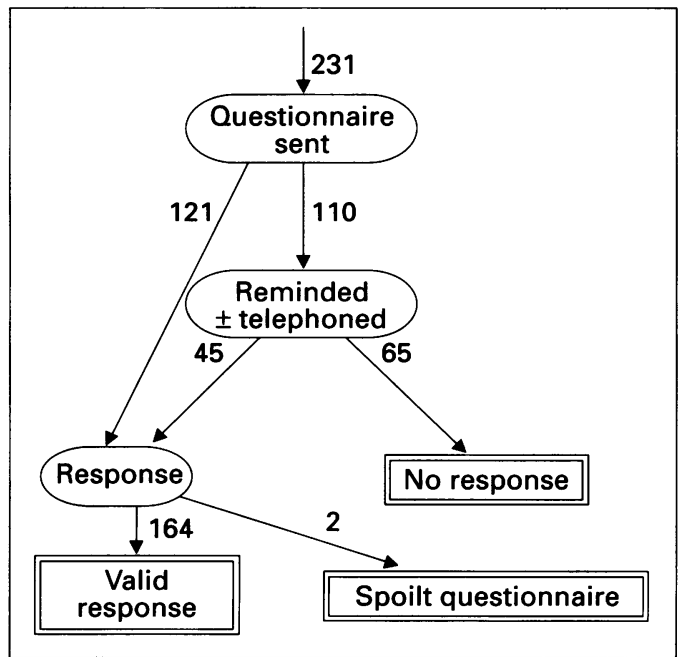

Figure 1 Flow chart outlining the survey process. The number of questionnaires following each path is shown.
Table 1 Contingency table relating the existence of an induction course to the existence of continuing departmental teaching for the 163 respondents who answered both questions. There is a significant association between the two variables: $P<0.002$ (Fisher's exact test).

\begin{tabular}{crrrr}
\hline & \multicolumn{2}{c}{ Departmental teaching } & Row total \\
\cline { 2 - 4 } & & Yes & No & \\
\hline Induction course & Yes & 141 & 7 & 148 \\
& No & 10 & 5 & 15 \\
\multicolumn{2}{c}{ Column total } & 151 & 12 & 163 \\
\hline
\end{tabular}

did not answer the question. The duration of the induction course was reported by 132 respondents; this varied widely from one to 40 hours, exceeding one day in 57\% (75/132) of instances, and exceeding one week in 5\% $(6 / 132)$ of instances. The longer courses tended to consist of an induction weekend followed by daily lectures for the first few weeks; the longest induction course continued every morning for six weeks. Most courses were based locally, although $14 \%$ of the courses (20/148) were held at least partly at a regional centre. An induction course tended to be provided in association with a programme of continuing departmental teaching (table 1). Continuing teaching was given to 141 (95\%) of the 148 respondents who reported receiving an induction course, whereas continuing teaching was given to only $10(67 \%)$ of the 15 respondents who reported receiving no induction course. This association is statistically significant (Fisher's exact test, $\mathrm{P}<0.002$ ).

Overall, 93\% (152/164) of the respondents received continuing departmental teaching, although this often amounted to less than two hours of teaching weekly (fig 2). Most commonly the teaching took the form of lectures and $x$ ray review (fig 3 ). Practical skill teaching, clinical audit, video films, and case presentations were also commonly used, although each was employed in fewer than half of responding departments. Only $8 \%$ of departments $(13 / 164)$ had a journal club. Other forms of teaching mentioned were "in department" tuition by senior staff, visits to local industrial sites, and attendance at fracture and review clinics.

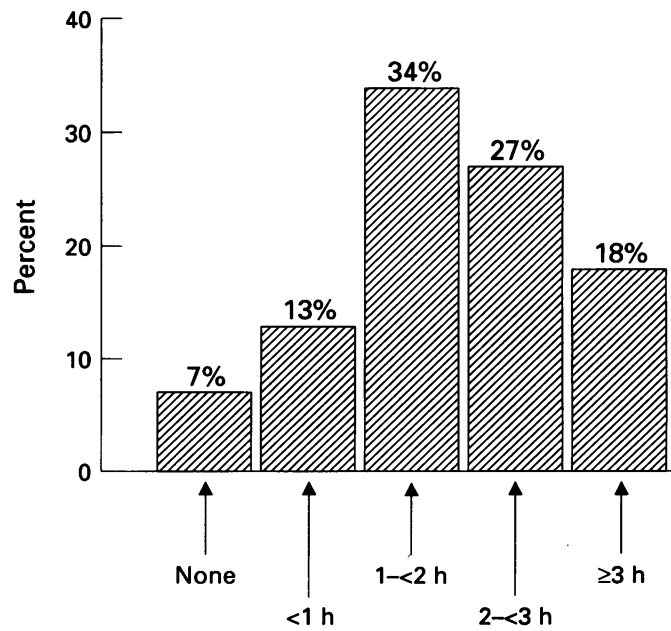

Figure 2 Frequency histogram showing the amount of time devoted to departmental teaching. Percentages among the 164 respondents are calculated to the nearest integer. 


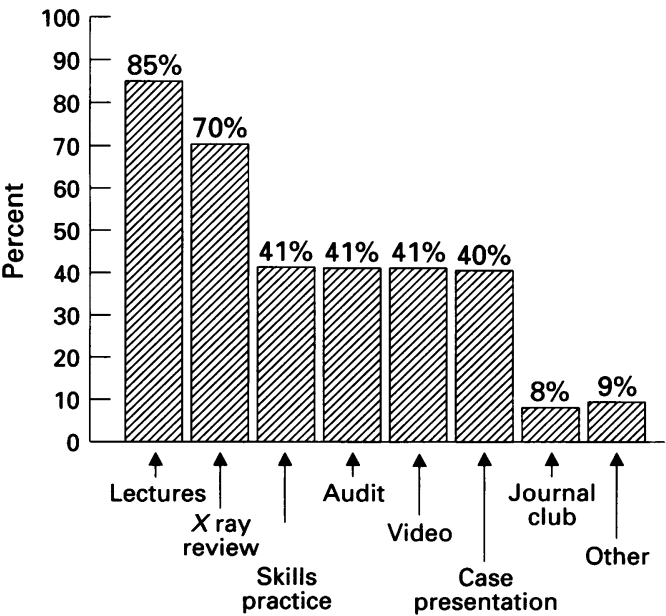

Figure 3 Frequency histogram showing the forms of departmental teaching received: these are not mutually exclusive. Percentages among the 164 respondents are calculated to the nearest integer.

The majority of respondents had a variety of reference and guideline material available to support them in their clinical work; only two respondents reported having no forms of clinical guidelines at all. The commonest form of guidelines were posters, general textbooks, departmental handbooks, and flow chart diagrams (fig 4). Some 16\% (26/164) of the respondents also reported having access to computer programs for decision support. Other sources of guidance mentioned were advice from senior colleagues and the use of preprinted patient proformas. Guideline material was referred to at least once a day by $46 \%$ $(75 / 164)$ and at least once a week by $87 \%$ (143/164) of the respondents (fig 5). One respondent commented "If I can find a guideline I'll use it". Interestingly, respondents felt that they referred to guidelines significantly more often than their colleagues $(P<0.02$, Wilcoxon signed-rank test). Some $60 \%$ of the respondents (98/164) thought that the available guidelines were adequate, while $29 \%$ (48/164) thought more comprehensive guidelines were needed. Comments included "the guidelines need to be more up-to-date", "they should be more organised", and "they should

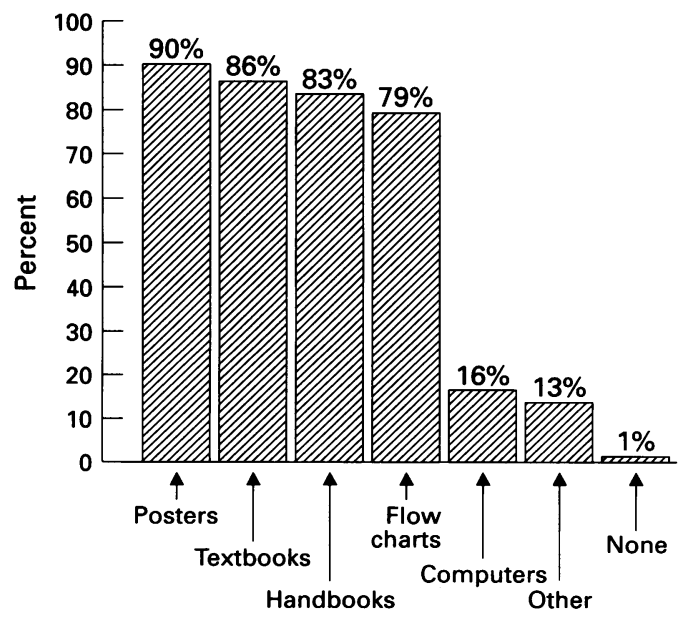

Figure 4 Frequency histogram showing the forms of guideline available. Percentages among the 164 respondents are calculated to the nearest integer.

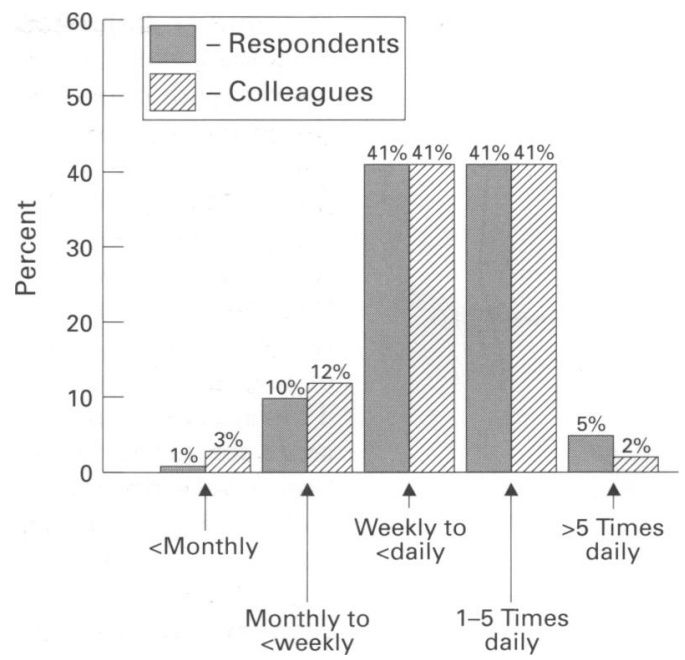

Figure 5 Histogram comparing the frequency of respondents' reference to guidelines with the perceived frequency of colleagues' reference to guidelines. Percentages among the 164 respondents are calculated to the nearest integer. Respondents feel that they refer to guidelines significantly more often than their colleagues $(P<0.02$, Wilcoxon signed-rank test).

be more accessible". Furthermore, a respondent was less likely to believe that the available guidelines were adequate if he or she received a longer teaching programme (table 2 ).

\section{Discussion}

In an ideal world, every patient attending an $\mathrm{A} \& \mathrm{E}$ department would be seen and treated by fully trained medical staff. However, with the present levels of senior A\&E staffing in the United Kingdom this is not practicable. In reality the majority of patients are seen by SHOs, particularly when attending out of normal working hours. This makes it especially important that junior staff receive structured teaching during their $\mathrm{A} \& \mathrm{E}$ attachment. A well organised teaching programme confers other potential benefits too. Heyworth et $a l^{5}$ noted that poor role definition was one of the strongest predictors of stress among SHOs in A\&E. A good induction and teaching programme should help to clarify this role. Not surprisingly, most junior doctors are eager to learn and are concerned about the quality of their education. ${ }^{6}$ This may have increasing significance for the many A\&E departments that are presently experiencing difficulties in recruiting SHOs.

In 1994 the NHS Management Executive recommended that, before starting a new post, every junior hospital doctor should receive an induction course appropriate to the specialty. ${ }^{7}$ This recommendation seems to be widely implemented in A\&E, with $90 \%$ of respondents in our survey reporting that they had

Table 2 Contingency table relating the amount of teaching received each week to the perceived adequacy of the clinical guidelines available. There is a significant interaction between the two variables: $P<0.02\left(\chi^{2}\right)$.

\begin{tabular}{rllll}
\hline & \multicolumn{2}{l}{ Weekly teaching } & \multirow{2}{*}{ Row total } \\
\cline { 2 - 3 } & $<2$ hours & $\geq 2$ hours & \\
\hline Guidelines & Adequate & 57 & 41 & 98 \\
Inadequate & 18 & 30 & 48 \\
Column total & 75 & 71 & 146 \\
\hline
\end{tabular}


attended an induction course specific to $\mathrm{A} \& \mathrm{E}$. However, the format of these courses varied widely, with courses lasting anything from one hour to six weeks. This suggests a need for standardisation of A\&E induction. ${ }^{8}$ Similarly, the majority (93\%) of the respondents in our survey received continuing departmental teaching. However, in $82 \%$ of cases (134/164; fig 2) the total amount of teaching was less than three hours per week, less than the minimum of four hours recommended by the BAAEM. ${ }^{8}$ This suggests that more time needs to be set aside for teaching in $A \& E$. Furthermore, this time could probably be used more imaginatively than at present; fewer than half of departments employ teaching methods such as skills practice, clinical audit, video films, and case presentation (fig 3).

If senior staff are not readily available, then the SHO must seek guidance when necessary from other sources (fig 4), each with its own potential advantages and disadvantages.

Textbooks are widely available in A\&E departments. However, textbooks soon become out of date, they often lack essential details, and they tend to be oriented towards disease description rather than problem solving. ${ }^{9}$ Furthermore, textbooks fail to take into account constraints imposed by variation in local resources (for example, presence or absence of a CT scanner) and local consultant preferences.

Departmental handbooks are also provided in the majority of $A \& E$ departments. Handbooks can be made pocket sized so that a copy is always conveniently at hand, and they can include specific information about the department too. ${ }^{10}$ However, a handbook is likely to be carried and consulted regularly only if it is comprehensive. The preparation and maintenance of such a handbook is a time consuming task.

Posters and broadsheets are another effective way of disseminating clinical guidelines, ${ }^{11}$ and they are widely displayed in A\&E departments. Again though, the information may not accord fully with local policies. Also, posters are easily damaged and defaced by wear and tear, and anyway they cannot cover the full spectrum of A\&E medicine.

Flow charts are widely used as a convenient representation for clinical algorithms. ${ }^{12-14} \mathrm{In}$ deed it has been shown repeatedly that flow charts are more comprehensible than prose for conveying instructions, both in terms of speed and accuracy, ${ }^{15-18}$ even if the prose is highly structured. ${ }^{19}$ Most A\&E departments have flow charts available in some form, although difficulties can arise in ensuring completeness and consistency.

Computers offer a potential solution to the problem of maintaining a large accessible data base of information on clinical management. Several groups have looked into the possibility of using computers to store, edit, and display clinical protocols. ${ }^{20-23}$ However, computer aids for the SHO are presently available only in a small minority of $A \& E$ departments $(16 \%$ in our survey).

Currently there is a good deal of interest in developing clinical guidelines, ${ }^{24-28}$ particularly in $\mathrm{A} \& \mathrm{E}$ medicine, where several studies have supported the need for better guidelines. ${ }^{12132930}$ However, the number of areas of $\mathrm{A} \& \mathrm{E}$ medicine for which guidelines are potentially useful is large, and guidelines would need to be tailored to each individual department to reflect local resources and consultant preferences. $^{31}$ The systematic development of formal guidelines, even for a quite limited clinical problem, can be a complex multidisciplinary task. ${ }^{32}$ The considerable effort involved can be justified only if the intended user, the A\&E SHO, would be interested in referring to the guidelines, and there are not simpler means to the same end (such as through more departmental teaching). However, our results show that SHOs refer to guidelines regularly, $87 \%$ of the respondents seeking information at least once a week, and $46 \%$ at least once a day; SHOs also appear to underestimate how often their colleagues do likewise. While most SHOs seem satisfied, a significant proportion (29\%) would like more detailed guidance to be available. Furthermore, the SHOs who requested more detailed guidelines had on average received more teaching than those who were satisfied with the available guidelines. This suggests that the development of comprehensive guidelines for A\&E SHOs is worthwhile.

Our survey is possibly limited by sampling bias. Despite every effort we managed to achieve a response rate of only $71 \%$, although this compares quite favourably with similar studies $\left(63 \%,{ }^{29} 72 \%{ }^{33}\right)$. It is conceivable that departments with active educational programmes are more likely to participate in a survey such as ours than departments who have none. However, the non-responding departments had no distinguishing characteristic. They were widespread geographically and included both small district general hospitals and large teaching hospitals.

In summary, therefore, our survey has shown that induction courses and teaching programmes are available in most but not all $\mathrm{A} \& \mathrm{E}$ departments in England and Wales, although the formats are variable. Clinical guidelines are also widely available, ranging in formality from general textbooks to flow chart algorithms, and they are used regularly by junior $A \& E$ doctors, many of whom would like more. We recommend that a national standard $\mathrm{A} \& \mathrm{E}$ induction course should be introduced and that all departments should have a regular and varied teaching programme. An individual within each department should be made responsible for overseeing the development and dissemination of local $A \& E$ protocols via a handbook, posters, and possibly a computer based system.

BST was supported by an EPSRC advanced fellowship in information technology, and CDM was supported by the former Oxford Regional Audit Executive.

\section{Appendix}

The first nine questions on the questionnaire were as follows.

1) Did you have an induction course specific to Accident and Emergency at the start of your SHO attachment? 
Please tick one box

$\square$ Yes

$\square$ No

If 'Yes' go to 2, if 'No' go to 3.

2) What form did the induction course take? (e.g. 'A morning of lectures')

3) Do you have a departmental teaching programme (apart from 'on the job' teaching)?
Please tick one box
$\square$ Yes
$\square$ No
If 'Yes' go to 4, if 'No' go to 6.

4) On average, how much time does this occupy each week?
Please tick one box
$\square$ Up to 1 hour
$\square$ Between 1 hour and up to 2 hours
$\square$ Between 2 hours and up to 3 hours
$\square$ More than 3 hours

5) Which forms does the teaching take?

Please tick any applicable boxes
$\square$ Case presentation
$\square$ X-ray review
$\square$ Lectures
$\square$ Clinical skills practice
$\square$ Video presentations
$\square$ Audit
$\square$ Journal club
$\square$ Other: please specify

6) Which forms of clinical guidelines (for investigation, diagnosis, and/or treatment) are available in your department?

Please tick any applicable boxes

$\square$ Posters and notices

$\square$ Printed flowcharts

$\square$ Computer programs

$\square$ Departmental handbooks

$\square$ Textbooks

$\square$ Other: please specify

$\square$ None

If 'None' then go to 9, otherwise go to 7 .

7) On average, how often do you refer to these sources of information?
Please tick one box
$\square$ Never
$\square$ Less than once a month
$\square$ Between once a month and up to once a week
$\square$ Between once a week and up to once a day
$\square$ Between one and five times per day
$\square$ More than five times per day

8) On average, how often do you think your colleagues refer to these sources of information?

Please tick one box

$\square$ Never

$\square$ Less than once a month

$\square$ Between once a month and up to once a week

$\square$ Between once a week and up to once a day

$\square$ Between one and five times per day

$\square$ More than five times per day

9) How adequate are the clinical guidelines you have available?

Please tick one box

$\square$ The existing guidelines are adequate

$\square$ More comprehensive guidelines are needed

$\square$ Other: please specify
1 Miller E, Montague A, Crone P, Kirby N. Quality assurance in Guy's hospital accident and emergency department. Health Trends 1992;24:38-40.

2 Vincent CA, Driscoll PA, Audley RJ, Grant DS. Accuracy of detection of radiographic abnormalities by junior doctors. Arch Emerg Med 1988;5:101-9.

3 BAAEM. British Association for Accident and Emergency Medicine, Leicester, 1993.

4 Morris F, Moore F. Case presentations in accident and emergency medicine. Oxford: Butterworth Heinemann, 1993.

5 Heyworth J, Whitley TW, Allison EJ, Revicki DA. Predictors of work satisfaction among SHO's during Predictors of work satisfaction among SHO's during
accident and emergency medicine training. Arch Emerg Med 1993;10:279-88.

6 Matheson KH. Stress and stress counselling. Postgrad Med f 1990;66:738-42

7 NHS Management Executive. Introduction of compulsory induction courses and changing the starting day for hospital medical and dental staff. Leeds: NHS Management Executive Circular EL(94)1, 1994.

8 BAAEM. Recommended teaching standards in accident and emergency departments. BAAEM Academic Committee Circular. London: Royal College of Surgeons, 1991.

9 Margolis CZ. Uses of clinical algorithms. fAMA 1983; 249:627-32.

10 McDonagh J, Clarke F, Veale D. How to do it: write a departmental handbook for junior staff. BMF 1993; 307:553-5.

11 McNally E, de Lacey G Lovell P, Welch T. Posters for accident departments: simple method of sustaining reduction in $x$ ray examinations. $B M \mathcal{F} 1995 ; 310: 640-2$.

12 Packer GJ, Goring CC, Gayner AD, Craxford AD. Audit of ankle injuries in an accident and emergency department. $B M \mathcal{F}$ 1991;302:885-7.

13 Stringer MD, Capps SNJ. Rationalising the management of swallowed coins in children. $B M \mathcal{Y}$ 1991;302:1321-2.

Swallowed coins in children. BMF 1991;302:1321-2.
14 Miller AC, Harvey JE. Guidelines for the management of Miller AC, Harvey JE. Guidelines for the managem

15 Wright $P$, Reid F. Written information: some alternatives to prose for expressing the outcomes of complex contingencies. F Appl Psychol 1973;57:160-6.

16 Kammann $R$. The comprehensibility of printed instructions and the flow chart alternative. Human Factors 1975; 17:183-91.

17 Vessey I, Weber R. Structured tools and conditional logic: an empirical investigation. Commun Assoc Comput Machinery 1986;29:48-57.

18 Margolis CZ, Cook CD, Barak N, Adler A, Geertsma A Clinical algorithms teach pediatric decision making more effectively than prose. Med Care 1989;27:576-92.

19 Scanlan DA. Structured flow charts outperform pseudocode: an experimental comparison. IEEE Software (September), 1989:28-36.

20 Cannon SR, Gardner RM. Experience with a computerised interactive protocol system using HEIP. Comput Biomed Res 1980;13:399-409.

21 Abendroth TW, Greenes RA. Computer presentation of clinical algorithms. MD Comput 1989;6:295-9.

22 Van Dessel PFHM, Hasman A, van der Linden CJ. ProtoVIEW: a workstation for the use of clinical algoProtoVIEW: a workstation for the use of clinical
rithms. Lecture Notes Med Informat 1991;45:233-7.

23 Todd BS. The verification and validation of clinical flow charts. Proceedings of the 7th Annual AAAI Workshop on charts. Proceedings of the 7th Annual AAAI Workshop on Seattle, 1994:95-7.

24 Gleadhill DNS, Thompson JY, Simms P. Can more efficient use be made of $x$ ray examinations in the accident and emergency department? BMF 1987;294:943-7.

25 Audet AM, Greenfield S, Field M. Medical practice guidelines: current activities and future directions. Ann Intern Med 1990;113:709-14

26 Clarke JA, Adams JE. The application of clinical guideline for skull radiography in the accident and emergency department: theory and practice. Clin Radiol 1990; 41:152-5.

27 Grimshaw JM, Russell IT. Effect of clinical guidelines on medical practice: a systematic review of rigorous evaluations. Lancet 1993;342:1317-22.

28 Farmer A. Medical practice guidelines: lessons from the United States. BMF 1994:307:313-7.

29 Aslam BH, Woods I. Intravenous sedation in accident and emergency departments: a nationwide survey. Ann $R$ Coll Surg Eng 1994;76:19-21.

30 Jenkins DP, Cooke MW, Glucksman EE. Audit of upper limb fracture management in an accident and emergency department. $\mathcal{F}$ Accid Emerg Med 1994;11:105-8.

31 Haines A, Hurvitz B, eds. Clinical guidelines: report of a local initiative. Exeter: Royal College of General Practitioners, 1992.

32 Magit AE, Stool SE. Clinical guideline development for otitis media: a report on methodology. Otolaryngol Head

33 Heyworth J, Whitley TW, Allison EJ, Revicki DA Correlates of work-related stress among consultants and
senior registrars in accident and emergency medicine. senior registrars in accident and
Arch Emerg Med 1993;10:271-8. 